\title{
REVISTAMARACANAN
}

\section{Atenção flutuante e deriva em W. G. Sebald}

\author{
Free-floating attention and drift in W. G. Sebald
}

\section{Dossiê}

\author{
Kelvin Falcão Klein \\ Universidade Federal do Estado do Rio de Janeiro \\ kelvin.klein@gmail.com
}

\begin{abstract}
Resumo: Este artigo busca investigar o caráter histórico dos modos de atenção na virada do século XIX para o XX, seguindo a argumentação de Jonathan Crary em Suspensões da percepção. Esse movimento inicial servirá de base para a exploração crítica da noção de "atenção flutuante", a partir de Sigmund Freud, e das categorias de "sociedade do espetáculo" e "deriva", a partir de Guy Debord. Por fim, o artigo propõe uma leitura da obra do escritor alemão W. G. Sebald, tendo como pano de fundo as noções e categorias delineadas na primeira parte.
\end{abstract}

Palavras-chave: Atenção flutuante; Deriva; Espetáculo; Imagem; W. G. Sebald.

\begin{abstract}
This paper investigates the historic nature of the modes of attention at the turn of the nineteenth to the twentieth century, following Jonathan Crary's argument in Suspensions of Perception. This initial movement will provide the basis for critical exploration of the concept of "free-floating attention", from Sigmund Freud, and the categories of "society of the spectacle" and "drift" from Guy Debord. Finally, the article proposes a reading of German writer W. G. Sebald work with the notions and categories outlined in the first part as background.
\end{abstract}

Keywords: Free-floating attention; Drift; Spectacle; Image; W. G. Sebald.

Artigo recebido para publicação em: Outubro de 2015

Artigo aprovado para publicação em: Novembro de 2015 


\section{O caráter histórico e os modos de atenção}

a á no início de Suspensões da percepção, livro de 1999, Jonathan Crary apresenta o "olhar" como um procedimento a ser apreendido e uma categoria a ser desnaturalizada. "Este livro se baseia na hipótese", escreve ele, "de que os modos pelos quais ouvimos, olhamos e nos concentramos atentamente em algo têm um profundo caráter histórico". ${ }^{1}$ Antes, portanto, de definir objetos, temas ou contextos de análise, Crary postula uma espécie de imperativo metodológico que deve preceder a emergência de qualquer texto ou imagem: os modos de atenção se transformam historicamente, o que equivale a dizer que respondem a ênfases diversas que são sempre construídas, articuladas discursivamente. Crary segue, até certo ponto, o lema reforçado por Fredric Jameson em $O$ inconsciente político, "historicizar sempre!", livro que "volta-se para a dinâmica do ato da interpretação e pressupõe, como sua ficção organizacional, que nunca realmente abordamos um texto de imediato, em todo o seu frescor como coisa-em-si mesma", mas como o "sempre-já-lido", "por meio de camadas sedimentadas de interpretações prévias". ${ }^{2}$ Para sustentar a analogia, é possível dizer que, na análise de Crary, os modos de atenção - ouvir, olhar, concentrar - passam de "coisas-em-si mesmas" para instâncias do "sempre-já-lido".

Depois de preparado o terreno metodológico, Crary vai aos poucos avançando com seus estudos de caso: são três capítulos dedicados, respectivamente, a Manet, Seurat e Cézanne, com análises que mesclam tanto um aporte iconológico (leituras de quadros específicos e das relações formais entre obras) quanto um aporte teórico (que vai desde contribuições da ótica, da física e da fisiologia, até a sociologia e a teoria literária). Se há um elemento comum que emerge da variedade de casos e exemplos levantados por Crary, é a insistência no caráter artificial e descontínuo da visão e da atenção, categorias que foram frequentemente isoladas do longo trajeto que as tornou possíveis. É isso que está por trás da definição de Crary sobre um dos possíveis significados da arte, que, no contexto da segunda metade do século XIX (especificamente em uma leitura cruzada de Seurat e Nietzsche), "não dizia respeito à representação, mas sim a uma relação de forças; a arte não era uma semiologia, mas uma física". ${ }^{3}$ A experiência da arte e, em paralelo com ela, a experiência da vida em sociedade torna-se legível historicamente a partir de um confronto de intensidades, confronto esse que amplia o espectro de análise, formando uma constelação crítica cujo objetivo não é a restrição do campo interpretativo possível, e sim sua variabilidade.

O percurso de Crary começa com a leitura de teóricos da percepção do século XIX (Wilhelm Wundt, Hermann von Helmholtz, Pierre Janet) até desembocar na tensa passagem do século XIX para o XX, com a consolidação do cinema, da sociedade do espetáculo e o

\footnotetext{
1 CRARY, Jonathan. Suspensões da percepção: atenção, espetáculo e cultura moderna. [Trad. Tina Montenegro.] São Paulo: Cosac Naify, 2013. p. 25.

2 JAMESON, Fredric. O inconsciente político: a narrativa como ato socialmente simbólico. [Trad. Valter Lellis Siqueira.] São Paulo: Editora Ática, 1992. p. 9.

${ }^{3}$ CRARY, Jonathan. Op. cit. p. 185.
} 
desenvolvimento de teorias influentes acerca desse conjunto de fenômenos, como as de Walter Benjamin, Sigmund Freud e Henri Bergson. "Com Bergson e Freud, em meados da década de 1890", escreve Crary, "o funcionamento antióptico da experiência perceptiva subjetiva passa a ser objeto de uma reflexão contínua e original, que a apresenta como um evento não direcional, acêntrico e multitemporal"; consequentemente, ele continua, "a percepção não implica mais uma relação sujeito-objeto, baseada num sujeito pontualmente localizado e na iluminação de objetos externos. Torna-se uma questão de relações de forças flutuantes e imanentes ao sujeito". ${ }^{4}$ (Grifo do autor)

Crary apresenta o processo de formação das bases de uma concepção não autonomista não apenas da imagem, mas do olhar que se torna possível diante da imagem. Tal cenário ganhará fôlego teórico e crítico nas primeiras décadas do século XX a partir das reflexões de Walter Benjamin, amplamente citado por Crary, como também a partir das reflexões de outros dois autores que não são mencionados em sua bibliografia: Carl Einstein e Aby Warburg. Tanto quanto Bergson e Freud, e na mesma época, Einstein e Warburg, com métodos distintos mas complementares, buscaram precisamente essa "multitemporalidade" que esvazia de importância o arcabouço exclusivamente óptico da "experiência perceptiva". Além disso, ao se deslocar o eixo "sujeito-objeto" em direção a um sistema de relação entre "forças flutuantes", não é apenas a lógica da representação - entendida como espelhamento, na arte, de uma realidade previamente estabelecida - que é minada, mas também aquela que remete o gesto artístico a uma expressão unilateral e autônoma. A expressão do "sujeito pontualmente localizado" é metamorfoseada em impressão não direcional. Daí decorre a proposição de Georges Didi-Huberman de que, para Carl Einstein, é o "anacronismo que fabrica a história", pois "ele tentou desenvolver uma dialética não hegeliana - uma concepção da história como 'luta' não apaziguável, irredutível a todo saber absoluto - que é também uma genealogia ao modo nietzscheano". ${ }^{5}$ (Grifo do autor)

Relembrar Einstein e Warburg consolida a própria argumentação de Crary, no sentido de mostrar o quão difundido estava o esforço de redirecionamento dos modos de atenção nesses últimos anos do século XIX e nas décadas iniciais do século XX. No epílogo que encerra o livro, Crary retorna a Freud, à multitemporalidade e à acentricidade presentes em suas teorias sobre a retenção e uso de imagens na dinâmica perceptiva do sujeito. Retomando uma carta que Freud escreve de Roma, Crary aborda aquilo que aqui nos interessa diretamente, ou seja, a noção de "atenção flutuante" e, ainda mais especificamente, a relação de tal atenção

\footnotetext{
${ }^{4}$ Ibidem. p. 329.

5 DIDI-HUBERMAN, Georges. "O anacronismo fabrica a história: sobre a inatualidade de Carl Einstein". In: ZIELINSKY, Mônica (Org.). Fronteiras: arte, crítica e outros ensaios. Porto Alegre: Editora da UFRGS, 2003. p. 32. Nota-se, portanto, como a obra de Carl Einstein, na perspectiva de Didi-Huberman, termina por levar às mesmas etapas metodológicas levantadas por Jonathan Crary, como a remissão à genealogia nietzschiana deixa clara. A ausência de Carl Einstein na argumentação de Crary, cuja "desatenção" seria passível de comentário, dada a própria natureza de sua investigação, poderia inicialmente indicar a validade de seu argumento inicial, ou seja, aquele que diz respeito ao "profundo caráter histórico" dos modos de ver e rever a tradição - o que gera, necessariamente, a multiplicidade crítica de percursos, que não são autônomos nem excludentes, sendo um deles aquele que levaria a Carl Einstein e Aby Warburg, como tento mostrar sumariamente aqui.
} 
flutuante com uma vivência comunitária que se pretende traduzida em discurso. Dois momentos da vivência de Freud são postos em contato por Crary: em primeiro lugar, a reflexão metodológica acerca dos procedimentos possíveis por parte do analista diante da fala do analisando; em segundo lugar, seu relato direto de uma experiência de estranhamento social, tornada possível pelo seu deslocamento tanto geográfico quanto funcional (o analista que se torna turista em uma cidade estrangeira). É no intervalo tenso entre geografias e funções sociais que Crary posiciona sua reflexão, e esse mesmo intervalo servirá para essa extensão em direção à literatura contemporânea que aqui proponho.

\section{A sociedade do espetáculo}

A carta de Freud utilizada por Crary foi escrita em Roma, em 22 de setembro de 1907, e enviada para sua família. O trecho selecionado por Crary apresenta o relato de Freud como flâneur na capital italiana, mesclando registros acerca da arquitetura tradicional (a Piazza Colonna) e dos novos artifícios de entretenimento para as massas (anúncios, o bonde elétrico, vendedores de jornais, o cinematógrafo). "Uma das características notáveis dessa carta", escreve Crary, "é como ela revela a transformação do status do observador, embora transmita um sentimento de modernização parcial e eternamente incompleta da experiência"; Freud "apresenta-nos uma cena urbana em que uma subjetividade individual e uma coletiva tomam forma em múltiplas imagens, sons, multidões, vetores, caminhos e informações, e sua carta registra uma tentativa particular de gerir e organizar cognitivamente esse campo sobrecarregado". ${ }^{6}$ O ponto fundamental da intervenção que Crary faz a partir da carta de Freud é indicar o duplo registro de seu relato: é tanto a experiência direta de um sujeito como uma tentativa de dar conta, textualmente, discursivamente, de uma experiência coletiva, de formação contingente de uma comunidade articulada a partir de um conjunto de modos de atenção postos em funcionamento, interna e externamente.

Como esse duplo registro pode extrapolar o contexto íntimo da carta familiar em direção a uma prática crítica? Crary escreve: "As camadas de atenção sugeridas nesse esboço de um ambiente espetacular nascente devem ser entendidas em relação a uma das mais formidáveis técnicas de atenção surgidas no século $X X$, um método concebido por Freud que estava no centro de seu projeto terapêutico", ou seja, uma "regra técnica" para terapeutas, que Freud chamava de "atenção uniformemente flutuante", uma "tentativa de definir um estado de receptividade no psicanalista que fosse proporcional à livre associação na fala do paciente"; nesse sentido, conclui Crary, "parte da modernidade de Freud deve-se à sua proposta de uma técnica para lidar com um fluxo de informações que não possuem estrutura ou coerência evidente". ${ }^{7}$

Tal técnica foi apresentada por Freud pela primeira vez em 1912, em um artigo intitulado "Recomendações ao médico que pratica a psicanálise". Segundo Freud, a tarefa

\footnotetext{
${ }^{6}$ CRARY, Jonathan. Op. cit. p. 358.

${ }^{7}$ Ibidem. p. 361.
} 
inicial do psicanalista é também a mais difícil, ou seja, aquela que diz respeito ao nível e à intensidade de atenção que deve ser reservada ao relato do analisando. Como é possível reter - e não apenas reter, memorizar, mas concatenar, relacionar e problematizar - as informações dadas por vários indivíduos ao longo de um mesmo dia? Tal técnica de retenção, explica Freud, "é bem simples", "rejeita qualquer expediente, como veremos, mesmo o de tomar notas, e consiste apenas em não querer notar nada em especial, e oferecer a tudo o que se ouve a mesma 'atenção flutuante', segundo a expressão que usei", evitando-se certa "fadiga da atenção", pois, continua Freud, "ao intensificar deliberadamente a atenção, começamos também a selecionar em meio ao material que se apresenta; fixamos com particular agudeza um ponto, eliminando assim outro, e nessa escolha seguimos nossas expectativas ou inclinações". 8 (Grifo do tradutor) É nesse ponto que Freud resume toda a argumentação de Crary em torno da articulação entre atenção e criação, entre subjetividade e comunidade, entre interioridade e exterioridade - pois Freud indica que o momento do insight do analista está mais ligado à fragmentação da atenção do que à restrição de seu foco. A fixidez da atenção frequentemente nos direciona a um ponto já conhecido, já experimentado. Por isso a ideia de que a atenção flutuante do analista funciona como contrapartida à associação livre do analisando, dois percursos paralelos e complementares que investem mais na incerteza do que na certeza.

Freud especifica a questão: é preciso "manter toda influência consciente longe de sua capacidade de observação e entregar-se totalmente à sua 'memória inconsciente', ou, expresso de maneira técnica: escutar e não se preocupar em notar alguma coisa", dessa forma, "os elementos do material que já formam um nexo ficarão à disposição consciente do médico; outros, ainda não relacionados, caoticamente desordenados, parecem primeiro submersos, mas emergem prontamente na consciência, tão logo o paciente traz algo novo, ao qual aqueles podem se ligar". ${ }^{9}$ (Grifo do autor) É importante notar como Freud faz do trabalho analítico algo em constante contato com o caos e a desordem, que não devem ser deixados de lado nem tomados como uma "etapa primitiva" do trabalho, e sim como elemento constituinte primordial - o caos é o substrato associativo que é reiteradamente visitado e explorado. Nas palavras de Crary, Freud, "como Cézanne", "projeta um contramodelo único de atenção, que resiste à noção de seleção e supera a inibição do periférico. Ele presume um estado ideal no qual é possível redistribuir a atenção de modo que nada fique de fora, que tudo seja

\footnotetext{
${ }^{8}$ FREUD, Sigmund. "Recomendações ao médico que pratica a psicanálise". In: Observações psicanalíticas sobre um caso de paranoia relatado em autobiografia ("O caso Schreber"): artigos sobre técnica e outros textos. [Trad. e notas de Paulo César de Souza.] São Paulo: Companhia das Letras, 2010. p. 148-149. Na ocorrência do termo "atenção flutuante", o tradutor apresenta a seguinte nota explicativa: "No original, gleichschwebende Aufmerksamkeit. Uma nota da Standard inglesa informa que, ao dizer que já usou a expressão, Freud alude provavelmente a uma passagem da 'Análise da fobia de um garoto de cinco anos' (1909), e que há uma ligeira diferença entre as duas passagens. De fato, no texto do 'Pequeno Hans' Freud usa gleiche Aufmerksamkeit, 'mesma atenção', enquanto o adjetivo que agora emprega é também formado de schwebend (do verbo schweben, pairar). Strachey utiliza evenlysuspended, que parece ser a melhor versão (não considerando a holandesa, que pode usar um composto exatamente igual ao alemão: gelijkzwevende). A antiga tradução espanhola utiliza flotante, a nova, argentina, optou por parejamente flotante, e a antiga versão francesa acrescenta aspas ao adjetivo: 'flottante'."

${ }^{9}$ Ibidem. p. 150.
} 
submetido a um nível reduzido de foco"; trata-se, finalmente, "de uma total inversão da hipótese da atenção como um 'holofote', pois esse tipo de 'seleção' iluminadora traz o risco de que se encontre apenas 'o que já se sabe'". ${ }^{10}$ (Grifo do autor)

Consolida-se, portanto, a partir de Freud (mas também Nietzsche, Bergson, Walter Benjamin, Carl Einstein, Aby Warburg, entre outros), um modo de atenção flutuante que permite associações e contatos, que não se pauta pela unidirecionalidade dos interesses nem pelo essencialismo dos métodos, abarcando também, no processo, a dimensão do caos e da desordem, pensados não como estados incontornáveis de improdutividade, mas como dimensões possíveis do trabalho analítico e interpretativo - pode-se dizer, finalmente, que se trata de um método comparatista de crítica e leitura. Um método comparatista, sim, mas que não investe na hierarquização dos elementos em contato, o que equivaleria ao paradigma anterior, dentro do qual o caos e a desordem - incorporados ao trabalho crítico a partir da atenção flutuante - são deixados de lado como ruído. Ainda no mesmo texto sobre a técnica, Freud indica um problema que serve aqui como analogia: "(...) quanto a pôr a descoberto o que é inconsciente para o doente, essa técnica não ajuda, apenas o torna ainda mais incapaz de superar resistências mais profundas, e em casos mais difíceis fracassa devido à insaciabilidade que foi despertada no paciente, que então gostaria de inverter a relação e acha a análise do médico mais interessante do que a sua". ${ }^{11}$ A sobreposição direta da interpretação sobre a experiência equivaleria àquilo que Freud denuncia como a descoberta daquilo que já se sabe - pois a "análise do médico" estaria ligada a tudo que já se conhece, de antemão, das questões levantadas.

Chegamos, finalmente, ao desenvolvimento de um método de trabalho - tanto prático (pois diz respeito à experiência) quanto teórico (experiência que se liga a um discurso) - que aposta mais na leitura do surpreendente do que no comentário sobre o tradicional. Como visto, Crary reconhece a emergência do método em dois momentos, na carta de 1907 e no ensaio de 1912, posicionando-os, no entanto, em um contexto mais amplo, que se desdobrará em direção às décadas seguintes: o cenário urbano visto por Freud em Roma, escreve Crary, apresenta "sinais da instauração de uma nova temporalidade, que subsiste como eterno presente desistoricizado, oscilando entre o tédio e a absorção, entre a imersão autodestruidora na multidão e uma insuportável solidão social. Com cada nova edição dos jornais negando a pretendida importância à edição anterior", continua Crary, "a aparição recorrente dos jovens vendedores faz parte do que Guy Debord viu como a erradicação da consciência histórica na

\footnotetext{
${ }^{10}$ CRARY, Jonathan. Op. cit. p. 361-362. Essa não é a primeira vez que Crary aproxima Cézanne e Freud em seu livro. Um pouco antes, Crary cita Lyotard e seu comentário de que "as obras de Cézanne e de Freud abandonaram o princípio da unificação psíquica e descobriram a produtividade e a criatividade dos processos perceptivos e psíquicos dispersos", e Crary continua: "Uma das contribuições de Freud, por volta da metade da década de 1890, foi postular um sistema de vida mental em que a percepção e a atenção representavam duas forças fundamentalmente diferentes. Em seu quixotesco 'Projeto para uma psicologia científica', Freud descreveu como a percepção, considerada uma interface do sistema nervoso com o mundo, era mais fortemente determinada por outra interface, entre a consciência e os estímulos 'acumulados' de desejos, memória e antecipações" (Idibem. p. 328). Chama a atenção o adjetivo "quixotesco".

${ }^{11}$ FREUD, Sigmund. Op. cit. p. 159.
} 
sociedade do espetáculo". ${ }^{12}$ Freud, portanto, dá testemunho de um incipiente regime espetacularizado de convivência, que se destaca por um "eterno presente desistoricizado" e por uma "erradicação da consciência histórica". Com isso retornamos ao primeiro parágrafo deste ensaio e também do livro de Crary, retomando a centralidade de uma crítica que trabalhe a partir da consciência do profundo caráter histórico dos artefatos culturais.

Em A sociedade do espetáculo, cuja primeira edição é de 1967, Debord fala da "destruição da história" por parte do espetáculo que visa ao eterno presente, o eterno retorno da novidade vazia, e o faz numa série de epigramas densos e diretos: "qualquer usurpador tenta fazer esquecer que acabou de chegar", "com a destruição da história, o próprio acontecimento contemporâneo logo se afasta para uma distância fabulosa, em meio a narrativas inverificáveis, estatísticas incontroláveis, explicações inverossímeis e raciocínios insustentáveis", "o espetáculo organiza com habilidade a ignorância do que acontece e, logo a seguir, o esquecimento do que, apesar de tudo, conseguiu ser conhecido", entre outros. ${ }^{13} \mathrm{O}$ espetáculo tenta obliterar, de todas as formas, justamente aquele percurso que Crary encontra em Freud - uma vivência que se cristaliza em discurso e que segue operativa e produtiva por conta do procedimento de retenção envolvido na atenção flutuante. O espetáculo faz do sujeito alguém que deve obrigatoriamente prestar atenção e absorver informação, sem que haja, no entanto, direcionamento e reflexão acerca dessa obrigatoriedade. O sujeito, dessa forma, torna-se refém de uma prática amnésica, desistoricizada, que se faz passar por experiência.

Fredric Jameson, no já referido $O$ inconsciente político, também se posiciona como crítico e leitor do espetáculo a partir de Debord. Para Jameson, essa configuração desistoricizada do contemporâneo é uma condição que a arte glosa continuamente e, ainda que seu livro não proponha "uma estética política e revolucionária", como ele mesmo aponta, também não "se preocupa em levantar mais uma vez os problemas tradicionais da estética filosófica", pois "a própria ausência desses problemas pode servir como comentário implícito a respeito deles", já que Jameson tenta "conservar uma perspectiva essencialmente historicista", na qual "nossas leituras do passado dependem de maneira vital de nossa experiência com relação ao presente e, particularmente, das peculiaridades estruturais daquilo que por vezes é chamado de société de consommation", ou seja, justamente "aquilo que Guy Debord chama de sociedade da imagem ou do espetáculo. O problema é que em uma sociedade como essa", finaliza Jameson, "saturada de mensagens e de experiências 'estéticas' de todos os tipos, as próprias questões referentes a uma estética filosófica mais antiga precisam ser radicalmente historicizadas, podendo-se esperar que se tornem irreconhecíveis nesse processo". ${ }^{14}$ (Grifo do autor) O que está em jogo no resgate que Crary faz de Freud, no entanto, ainda não é a historicização de questões estéticas antigas partindo de um contexto já impregnado do

\footnotetext{
12 CRARY, Jonathan. Op. cit. p. 362-363.

13 DEBORD, Guy. A sociedade do espetáculo. [Trad. Estela dos Santos Abreu.] Rio de Janeiro: Contraponto, 1997. p. 177-179.

${ }^{14}$ JAMESON, Fredric. Op. cit. p. 11.
} 
espetáculo, e sim a historicização de um momento de transformação, de passagem do domínio da história para o domínio do "presente perpétuo". ${ }^{15}$

Em ensaio de 2007, que dá título ao seu livro O espectador emancipado, Jacques Rancière também retorna a Guy Debord e à questão do espetáculo, exatos quarenta anos depois da publicação de $A$ sociedade do espetáculo. "Qual é a essência do espetáculo segundo Guy Debord?", pergunta Rancière, que segue: "É a exterioridade. O espetáculo é o reino da visão, e a visão é exterioridade, ou seja, desapossamento de si. A doença do espectador pode resumir-se numa fórmula breve: 'Quanto mais ele contempla, menos ele é'", e Rancière finaliza: "O que o homem contempla no espetáculo é a atividade que lhe foi subtraída, é sua própria essência, que se tornou estranha, voltada contra ele, organizadora de um mundo coletivo cuja realidade é a realidade desse desapossamento". ${ }^{16}$ As teses de Rancière sobre a emancipação estão ligadas a um livro seu anterior, O mestre ignorante (de 1987), que é retomado aqui e desdobrado em direção ao espectador, o espetáculo e a dinâmica entre passividade e atividade na fruição estética contemporânea. A emancipação, tal como a entende Rancière nesse arco longo de sua obra, é a possibilidade de articular pertencimento e fuga, ou ainda, para articulá-lo com a cena de que nos ocupamos anteriormente, a possibilidade de articular experiência e discursividade, atenção restrita e atenção flutuante. A emancipação do espetáculo ocorre de forma tensa e ambivalente, na medida em que o sujeito absorve criticamente o espetáculo ao dizer de si, discursivamente, como espectador. ${ }^{17}$

Ainda que o que esteja em questão aqui não seja uma espécie de "gênese e estrutura da Sociedade do espetáculo" - para relembrar o projeto de Hyppolite em torno a Hegel pode-se dizer que a ideia de que o espectador se atualiza como sujeito crítico a partir do contato com o espetáculo guarda uma analogia produtiva com a noção de atenção flutuante: é o esvaziamento da atenção restrita que permite a inclusão de material desconhecido na experiência perceptiva, ou seja, é preciso atravessar a superficialidade para alcançar a criticidade. Trata-se, nas palavras de Crary, de uma "oscilação constante entre o pertencimento e a desorientação", pois a "atenção moderna inevitavelmente flutua entre esses polos", é tanto "uma perda do eu que oscila indefinidamente entre uma evaporação emancipadora da interioridade e da distância" quanto "uma incorporação entorpecedora às

\footnotetext{
15 DEBORD, Guy. Op. cit. p. 175: "A sociedade modernizada até o estágio do espetacular integrado se caracteriza pela combinação de cinco aspectos principais: a incessante renovação tecnológica, a fusão econômico-estatal, o segredo generalizado, a mentira sem contestação e o presente perpétuo".

16 RANCIĖRE, Jacques. O espectador emancipado. [Trad. Ivone C. Benedetti.] São Paulo: WMF Martins Fontes, 2012. p. 12.

${ }^{17}$ Rancière faz do espectador um desdobramento do espetáculo, dando a essa noção de espectador uma feição mais de procedimento do que de identidade. É distinto, portanto, do espectador que surge em Henri Bergson quando este fala da memória e do déjà $v u$ - Paolo Virno, assim como Crary, revisita Bergson e Nietzsche em busca de uma articulação entre déjà vu e um incipiente esvaziamento do presente, um "fim da História": "já que o presente veste as roupas de um passado irrevogável, renunciase a incidir em seu decurso (...). O sujeito torna-se espectador das próprias ações, como se fizessem parte de um roteiro já conhecido e invariável. Espectadores atônitos, às vezes irônicos, com frequência inclinados ao cinismo". In: VIRNO, Paolo. El recuerdo del presente: ensayo sobre el tiempo histórico. [Tradução ao espanhol de Eduardo Sadier.] Buenos Aires: Paidós, 2003. p. 16-17. Fica claro que a emergência histórica da sociedade do espetáculo faz parte indissociável do processo de emancipação do espectador.
} 
múltiplas engrenagens do trabalho, da comunicação e do consumo", e conclui remetendo a Freud: "portanto, o espaço plural e híbrido dessa praça romana no final do verão de 1907 prenuncia que a sociedade do espetáculo não está irrevogavelmente destinada a transformarse num regime contínuo de separação, nem numa mobilização coletiva nefasta", em vez disso, "será uma miscelânea de efeitos flutuantes, nos quais os indivíduos e os grupos vão se reconstituir de modo contínuo, seja criativa ou reativamente". ${ }^{18}$

São exatos 60 anos que separam o passeio de Freud em Roma da publicação de $A$ sociedade do espetáculo de Debord, mas, ainda assim, a concatenação entre experiência e discursividade crítica em Freud já é uma estratégia possível de convivência com tal "miscelânea de efeitos flutuantes". Da mesma forma, Crary fala de uma "evaporação emancipadora da interioridade e da distância", evocando com isso também o espectador emancipado de Rancière, que combina a "perda do eu" com a incorporação ao trabalho, à comunicação e ao consumo. Outro comentador de Debord, Mario Perniola, dá um diagnóstico semelhante: "Para Debord, a sociedade do espetáculo integrado nos introduz em um presente perpétuo que abole a experiência da história, pois inflacionando a importância da novidade destrói qualquer critério de medida". ${ }^{19}$ além de oferecer também um método de enfrentamento, dada pelo próprio Debord via carta: "acreditamos na necessidade de dominar criticamente esses momentos (a teoria, a expressão, a agitação, etc.) em diferentes níveis. Está evidente para todos que não podemos nos reduzir a uma espécie de pura imediação". ${ }^{20}$ Dominação crítica em diversos níveis, portanto, e não a lamentação cujo objeto é um tempo pregresso utópico de diferenciação restrita entre sujeito e objeto. Daí reforça-se, portanto, a preponderância da atenção flutuante como método perceptivo em um contexto saturado, que permite a reconstituição "de modo contínuo", como aponta Crary, criativa e reativamente.

\section{Literatura e atenção flutuante}

A carta de Freud serviu a um duplo propósito: localizar historicamente a emergência de certo contexto de proliferação de imagens - aquilo que Debord chama sociedade do espetáculo - e, em paralelo, evidenciar um método de elaboração crítica de tal contexto, método que diz respeito tanto à atenção flutuante quanto ao esforço de passagem da experiência à escrita. Isto posto, chega o momento de esboçar aquilo que entendo como um desdobramento, na literatura contemporânea, de tal concomitância de experiência, discurso e sociedade do espetáculo. A obra do escritor alemão W. G. Sebald (1944-2001) servirá de estudo de caso, não só por conta da ampla repercussão mundial que teve - com romances como Austerlitz (2001), Os anéis de Saturno (1995) e Os emigrantes (1992), já traduzidos também no Brasil -

\footnotetext{
18 CRARY, Jonathan. Op. cit. p. 364.

19 PERNIOLA, Mario. Enigmas: egípcio, barroco e neobarroco na sociedade e na arte. [Trad. Carolina Pizzolo Torquato.] Chapecó: Argos, 2009. p. 29.

20 Idem. Desgostos: novas tendências estéticas. [Trad. Davi Pessoa Carneiro.] Florianópolis: Editora da UFSC, 2010. p. 206. Perniola informa que a citação vem de uma carta que Debord escreveu a ele em 18 de novembro de 1967.
} 
, mas também pelos temas que toca (a imagem, o trauma, o questionamento da autoridade do narrador) e pelos autores a que faz referência continuamente (Walter Benjamin, Theodor Adorno, Robert Walser, Vladimir Nabokov, Jorge Luis Borges, entre muitos outros). O esforço aqui será o de transitar de forma transversal entre alguns de seus textos, evidenciando os momentos em que Sebald toca os temas que são centrais para minha argumentação - ou seja, o caráter histórico das imagens, dos modos de atenção e da articulação escritural da vivência na sociedade do espetáculo.

Um recorte se faz sempre necessário, ainda mais se lembrarmos as palavras de Dolf Oehler: "Parece que tudo ou quase tudo já foi dito sobre a obra de Sebald, cuja escrita tão singular, inspirada inteiramente pela vergonha e pela tristeza, não deixa de fascinar o público e de chamar a atenção de comentaristas do mundo inteiro". ${ }^{21}$ A presença recorrente de imagens em seus textos e os comentários que tece a respeito delas asseguram que Sebald tinha sempre em mente o problema da articulação entre espetáculo, memória e história. A ideia de espetáculo como esvaziamento da história e emergência de um presente contínuo é recorrente na poética de Sebald, preocupado que era com certo pacto de silêncio que, segundo ele, teria acometido a Alemanha no período pós-guerra - um silêncio que dizia respeito tanto ao legado nazista quanto ao horror da destruição da Alemanha por parte dos bombardeios dos aliados: "a reconstrução alemã equivaleu, após as devastações causadas pelos inimigos de guerra, a uma segunda aniquilação, realizada em fases sucessivas, de sua própria história anterior (...), direcionando a população, sem exceção, para o futuro e obrigando-a ao silêncio sobre aquilo que enfrentara", escreve Sebald em Guerra aérea e literatura. ${ }^{22}$

Debord, que nasceu em 1931, foi, portanto, contemporâneo de Sebald. Compartilhavam uma inadequação diante dos rumos sociais e políticos de seus respectivos países e, além disso, uma aguda sensibilidade às imagens e seu potencial narrativo. Contudo, o ponto fundamental que permite a aproximação entre eles é uma atividade já referida por Freud em sua carta de Roma e comentada por Crary: a caminhada, ou deambulação, que permite a ativação da atenção flutuante e gera material para a escritura posterior. Toda produção escrita de Sebald envolve o ato de caminhar, seja observado em outros - como no início de Vertigem: "Em meados de maio de 1800, Napoleão e seus trinta e seis mil homens atravessaram o Grande São Bernardo, uma empreitada considerada até então como praticamente impossível" $-{ }_{,}^{23}$ seja como atividade do próprio narrador, como em Os emigrantes: "No hotel completamente deserto eu era toda vez assaltado por uma sensação tão avassaladora de desorientação e futilidade que, ao menos para ter a ilusão de um certo norte, me punha a caminho da cidade, onde (...) vagava sem rumo entre os prédios monumentais do século XIX". ${ }^{24}$ Debord, por sua vez, já em fins da década de 1950, desenvolve conceitos como

\footnotetext{
${ }^{21}$ OEHLER, Dolf. "Alucinações e alegorias: W. G. Sebald se recorda de W. Benjamin, leitor de Paris". Novos estudos CEBRAP, São Paulo, n. 89, mar., 2011., p. 151-161.

22 SEBALD, W. G. Guerra aérea e literatura: com um ensaio sobre Alfred Andersch. [Trad. Carlos Abbenseth e Frederico Figueiredo.] São Paulo: Companhia das Letras, 2011. p. 16-17.

${ }^{23}$ Idem. Vertigem: sensações. [Trad. José Marcos Macedo.] São Paulo: Companhia das Letras, 2008. p.7.

24 Idem. Os emigrantes: quatro narrativas longas. [Trad. José Marcos Macedo.] São Paulo: Companhia das Letras, 2009. p. 158.
} 
os de "deriva", "psicogeografia" e "détournement", calcados na experiência direta da caminhada pelas cidades, caminhada pensada como intervenção política nos espaços comunitários. ${ }^{25}$

É precisamente nessa deriva que a atenção flutuante entra em ação. Para Sebald e Debord, o que está em jogo na caminhada não é a busca de si ou a oportunidade de reflexão acerca dos próprios caminhos e anseios; pelo contrário, não há objetividade na deriva, que é pautada pela "desorientação", pela "ilusão de um certo norte" e pela ausência de rumo de que fala Sebald em Os emigrantes, como citado anteriormente. Ou, para usar o vocabulário de Crary quando comenta Bergson e Freud, a deriva é "um evento não direcional, acêntrico e multitemporal". ${ }^{26}$ A ideia de multitemporalidade é central para Sebald, e frequentemente aquilo que surge como surpresa em sua narração-caminhada, e em seu exercício análogo de atenção flutuante, diz respeito a uma percepção das impurezas do tempo.

No último livro que publica em vida, Austerlitz, que, segundo Oehler, "é seu verdadeiro testamento espiritual", ${ }^{27}$ Sebald dá vários exemplos de sua peculiar mistura de atenção flutuante, multitemporalidade e reflexão sobre as imagens. O livro é narrado em primeira pessoa por um homem muito semelhante a Sebald - um alemão, professor de literatura, que mora na Inglaterra. O narrador relata seus encontros com Jacques Austerlitz, um sobrevivente da Shoah que durante décadas desconheceu seu nome verdadeiro, pois foi adotado ainda pequeno por um casal inglês durante a guerra. Dois homens, portanto, que falam dos assuntos mais variados (poesia, arquitetura, selos, mochilas, etimologias) e refletem a respeito do tempo, da percepção da passagem do tempo e, sobretudo, do caráter artificial das marcações de passagem do tempo. Deu-se, escreve o narrador, "naquele tempo, agora já tão remoto, embora determine até hoje nossas vidas". ${ }^{28}$ "Como é pouco o que logramos conservar na memória, como tudo cai constantemente no esquecimento com cada vida que se extingue", escreve ele mais adiante, transmitindo as palavras de Austerlitz, "como o mundo por assim dizer se esvazia por si mesmo, na medida em que as histórias ligadas a inúmeros lugares e objetos por si sós incapazes de recordação não são ouvidas, não são anotadas nem transmitidas por ninguém". ${ }^{29}$

É possível dizer que o romance Austerlitz começa já como uma deriva sem rumo prévio, cujo principal ponto de transformação é o encontro do narrador com Jacques Austerlitz - um encontro por acaso, que permitirá a reunião de duas experiências de atenção flutuante que

\footnotetext{
25 "'Entre os diversos procedimentos situacionistas, a deriva se apresenta como uma técnica de passagem rápida por ambiências variadas. O conceito de deriva está indissoluvelmente ligado ao reconhecimento de efeitos de natureza psicogeográfica e à afirmação de um comportamento lúdico-construtivo, 0 que 0 torna absolutamente oposto às tradicionais noções de viagem e de passeio.' Começa assim o célebre texto-manifesto de 1958 em que Guy Debord descreve e normatiza a prática da deriva, que consiste em perambular, sobretudo a pé, mas eventualmente também de outras formas, sem rumo predefinido, escolhendo ao acaso, ou com base em sensações e impressões extemporâneas, a direção a ser tomada a cada momento." In: VISCONTI, Jacopo Crivelli. Novas derivas. São Paulo: WMF Martins Fontes, 2014. p. VII.

${ }^{26}$ CRARY, Jonathan. Op. cit. p. 329.

27 OEHLER, Dolf. Op. cit. p. 151.

28 SEBALD, W. G. Austerlitz. [Trad. José Marcos Macedo.] São Paulo: Companhia das Letras, 2008. p. 13.

${ }^{29}$ Ibidem. p. 28.
} 
serão contrastadas e articuladas discursivamente ao longo da narração. Depois de perambular pelo zoológico de Antuérpia, o narrador retorna à estação de trens e lá, na sala de espera, encontra pela primeira vez Austerlitz. Em Austerlitz, nenhuma experiência tem a pretensão de ser direta, pura ou essencial. A narração é feita muitos anos depois dos encontros, e esses eram, por vezes, um confronto dialógico de percepções do passado, tanto de Austerlitz quanto do narrador. Tais percepções do passado, no entanto, eram complexificadas a partir da deriva específica na qual ambos estavam inseridos. O percurso realizado no presente levava ao passado, e esses dois momentos incertos são, muitos anos depois, resgatados pelo narrador que tenta dar conta de sua experiência, da experiência de Austerlitz e do produto híbrido do contato entre os dois. O curso dos acontecimentos no romance é dado pela digressão, uma digressão que se pauta pela atenção flutuante, que seleciona objetos, cenas e paisagens sem hierarquização ou desejo de homogeneidade.

Em Austerlitz, toda deriva leva a uma psicogeografia ou a uma reflexão psicogeográfica, na qual se procura problematizar uma vivência no tempo e no espaço a partir da movimentação. Em sua história crítica da psicogeografia, Merlin Coverley argumenta que, como seria de se esperar, ainda que o termo tenha conhecido maior divulgação a partir do texto-manifesto situacionista de Debord em 1958, a psicogeografia (como prática e conceito) pode ser rastreada nas obras de autores os mais variados (Rousseau, Santo Agostinho, Diderot), sempre apontando, em maior ou menor grau, ao estabelecimento de uma experiência crítica do corpo em relação ao tempo e ao espaço. ${ }^{30}$ Já no início de Austerlitz, Sebald apresenta uma cena na qual articula atenção flutuante, deriva e psicogeografia: "Naquele dia, depois que deixamos nossos postos de observação no passeio público para caminhar pelo centro da cidade", escreve o narrador, "Austerlitz falou ainda longamente sobre as marcas de sofrimento que, como ele dizia saber, atravessam a história com inúmeras linhas delgadas. Em seus estudos sobre a arquitetura das estações de trem", continua ele, "ele nunca conseguia tirar da cabeça os pensamentos da aflição da despedida e do medo de lugares estranhos, embora tais emoções obviamente não façam parte da história da arquitetura". ${ }^{31}$

O encadeamento é ao mesmo tempo sutil e revelador: o diálogo dá-se sempre em movimento, durante caminhadas, e a indicação de que Austerlitz "falou ainda longamente" mostra que se trata de um fragmento de uma conversa anterior, da qual temos acesso apenas a esse breve momento; em seguida, surgem as "marcas de sofrimento" que atravessam a história com "inúmeras linhas delgadas", marcas, no entanto, que não são reconhecíveis na história oficial ou padrão. Tanto a multitemporalidade quanto a articulação entre despersonalização e experiência estão em jogo quando o narrador escreve que Austerlitz, a respeito das marcas de sofrimento presentes na história, "dizia saber" uma sabedoria que envolvia os "pensamentos da aflição da despedida e do medo de lugares estranhos". Nesse ponto da narrativa, a referência ainda não é clara, mas Austerlitz comenta a deriva conjunta (dele e do narrador) pela arquitetura de Antuérpia tendo como pano de fundo sua experiência

\footnotetext{
${ }^{30}$ COVERLEY, Merlin. Psychogeography. Harpenden: Pocket Essentials, 2006. p. 7-25.

${ }^{31}$ SEBALD, W. G. Op. cit. p. 18.
} 
de fugitivo do extermínio nazista na infância. A percepção do tempo por parte do sujeito é sempre alheia ao fluxo coordenado da cronologia, está sempre em discordância ou descompasso. "De que modo diferem as coisas imersas no tempo daquelas que jamais foram por ele tocadas?", pergunta o narrador mais adiante e prossegue: "Não se poderia dizer, disse Austerlitz, que o tempo ao longo dos séculos e dos milênios foi ele próprio pouco contemporâneo?", além disso, "os mortos estão fora do tempo, os moribundos e todos os doentes nos leitos das suas casas e dos hospitais, e não são só eles, pois um tanto de infelicidade pessoal já basta para nos cortar de todo o passado e de todo o futuro". ${ }^{32}$

O procedimento da deriva, na literatura de Sebald, instaura uma modalidade do ato de ver que é tanto descontínua quanto crítica. Por conta da atenção flutuante, o olhar não reitera aquilo que já sabe, mas sobrepõe ao mundo material novas conexões discursivas. Por isso a arquitetura da cidade pode remeter ao passado, aos mortos e às imagens que tentam dar conta daquilo que já não é mais acessível. ${ }^{33}$ "Não me parece, disse Austerlitz, que compreendemos as leis que governam o retorno do passado", escreve o narrador de Sebald, "mas sinto cada vez mais como se o tempo não existisse em absoluto, somente diversos espaços que se imbricam segundo uma estereometria superior, entre os quais os vivos es mortos podem ir de lá para cá como bem quiserem". ${ }^{34}$ Esse trecho reforça a maleabilidade crítica do método da atenção flutuante - quando afirma a incompreensão das leis que governam a dinâmica da memória, por exemplo -, ao mesmo tempo em que postula uma ancoragem possível dentre tantas, ou seja, ao mesmo tempo em que apresenta uma estratégia de deriva, sua "estereometria superior", que não se pretende definitiva ou universal, e sim válida quando contraposta a uma experiência precisa, veiculada discursivamente por um sujeito que reconhece tal experiência como contingente.

Mais adiante, quase ao fim do romance, Austerlitz volta à questão (é preciso sempre atenção na diferenciação da voz de Austerlitz e do narrador, que vão aos poucos se mesclando, trocando posições, como se à multitemporalidade fosse acrescentada também a multi-identidade): "Quando, por exemplo, nos meus caminhos pela cidade, olho para aqueles silenciosos pátios internos onde nada mudou durante séculos, sinto quase fisicamente como a

\footnotetext{
32 Ibidem. p. 103. Douglas Pompeu, em sua dissertação de mestrado sobre Austerlitz e tendo visitado os arquivos de Sebald em Marbach, afirma que o autor não só foi meticuloso na organização do próprio arquivo como colecionava inúmeros conjuntos de fotografias, que the serviam como aide-mémoire para o trabalho literário: são "cinco caixas com 45 pastas conservam fotografias, negativos, ilustrações, cartõespostais, selos e outros tipos de imagem que seguem, em boa parte, a ordenação de um índice alfabético, segundo o qual cada letra se refere a uma espécie de etiqueta, por exemplo: a letra A remete às fotos de Austerlitz e Ausgewanderten, a letra C a 'Castle' e 'Casement' e F à 'Familiengeschichte'". In: POMPEU, Douglas Valeriano. As sombras do real em Austerlitz: investigação sobre a fotografia em W. G. Sebald. Dissertação (Mestrado em Língua e Literatura Alemã) - Faculdade de Filosofia, Letras e Ciências Humanas, Universidade de São Paulo, São Paulo, 2012. p. 134.

33 "Em um ensaio sobre Vladimir Nabokov, incluído na coletânea Campo santo (um título que já nos remete diretamente à questão do contato entre vivos e mortos), Sebald dá conta de uma junção do tema do sonho com o tema dos mortos. O ensaio tem o sugestivo título 'Texturas oníricas: uma breve nota sobre Nabokov'. As mais brilhantes passagens da fiç̧ão de Nabokov, segundo Sebald, 'dão a impressão de que nossas ações cotidianas estão sendo observadas por outras espécies, ainda desconhecidas a qualquer sistema taxonômico, cujos emissários às vezes protagonizam as cenas criadas pelos vivos'." In: KLEIN, Kelvin Falcão. "Entre vivos e mortos: imagem e memória". Literatura e Autoritarismo (UFSM), v. 8. p. 9, 2012. p. 9; 4-15.

${ }^{34}$ SEBALD, W. G. Op. cit. p. 182.
} 
corrente do tempo se retarda no campo gravitacional das coisas esquecidas. Todos os momentos da nossa vida", continua ele, "me parecem então reunidos em um único espaço, como se os acontecimentos futuros já existissem e aguardassem apenas que chegássemos finalmente até eles, tal como nós, tendo aceitado um convite, chegamos a uma determinada casa a uma determinada hora". ${ }^{35}$ Novamente, os "caminhos pela cidade" ativam um olhar que se faz penetrar pela "corrente do tempo" e pelo "campo gravitacional das coisas esquecidas". O uso de fotografias no corpo do texto de Austerlitz (são quase 100 reproduções ao longo de 287 páginas) não visa à documentação ou à ilusão de veracidade, nem mesmo à comprovação de uma pretensa presença do narrador em tal ou qual situação. As imagens são testemunhas da porosidade do tempo, não estão ali, em Austerlitz, para a contemplação desistoricizada ou para celebração de um presente eterno - como seria de praxe na versão mais pura dos comentários sobre a sociedade do espetáculo -, e tampouco para fixar a narração no real, direcionando-a para uma espécie de campo da certeza historiográfica.

O próprio Austerlitz indica o modo como entende o trabalho da imagem. "No trabalho do fotógrafo, sempre me encantou o instante em que as sombras da realidade parecem surgir do nada sobre o papel em exposição, tal como recordações", escreve o narrador segundo as palavras de Austerlitz, "que nos ocorrem no meio da noite e que tornam a escurecer rapidamente caso se tente agarrá-las, à maneira de uma prova fotográfica deixada muito tempo no banho de revelação". ${ }^{36}$ O procedimento da atenção flutuante é reiterado - as "sombras da realidade" surgem do nada, sem previsão ou aviso, e a tentativa de "agarrá-las" de forma direta, ou seja, de restringir o foco abruptamente, elas "tornam a escurecer rapidamente". A imagem é materialidade (as fotos colecionadas em caixas de sapato de que fala Austerlitz $)^{37}$ mas também é processo da memória, contato, especulação.

Essa potencialidade do uso da imagem advém, no caso de Sebald, de sua reflexão a respeito da destruição da Alemanha na II Guerra Mundial e o silêncio daí decorrente, como já apontado anteriormente. Tal articulação entre destruição e silêncio, que "determina a fisionomia da Alemanha até hoje", gerou, nas palavras de Sebald em Guerra aérea e literatura, um "déficit" historiográfico, que no decurso dos anos se torna "para mim cada vez mais claro, escandaloso, recorda-me que eu cresci com a sensação de que algo me era escondido, em casa, na escola e também pelos escritores alemães cujos livros eu lia na esperança de poder aprender mais sobre as monstruosidades dos bastidores da minha própria vida". ${ }^{38}$ Assim como Freud, que, a partir de uma vivência particular e de uma reflexão crítica igualmente única, aborda a incipiente sociedade do espetáculo, Sebald, com os mesmos elementos, dá uma nova

\footnotetext{
35 Ibidem. p. 250.

${ }^{36}$ Ibidem. p. 80.

37 Ibidem. p. $121 ; 151$.

${ }^{38}$ Idem. Guerra aérea e literatura. p. 66. Esse trecho de Sebald, que é tanto ensaio quanto memória, ecoa em uma passagem de Austerlitz na qual Austerlitz, em conversa com o narrador, relembra sua infância (já depois da fuga) e sua crença em fantasmas, evidentemente rechaçada pelo pai adotivo: "De fato, durante todos os anos que passei na casa do pregador em Bala, jamais me livrei da sensação de que algo bastante óbvio, manifesto em si mesmo, me era ocultado". In: SEBALD, W. G. Austerlitz. p. 58. Não seriam os "fantasmas" de Austerlitz análogos às imagens da destruição e dos mortos a que Sebald não tinha acesso em sua infância?
} 
perspectiva à noção de "eterno presente" do espetáculo. As imagens não são inerentemente ligadas ao espetáculo - e sua tendência à desistoricização -, pois podem ser utilizadas, argumenta Sebald tendo em vista o pós-guerra na Alemanha, como forma de questionar o silêncio e reconciliar criticamente o déficit historiográfico. É preciso fazer uso daquilo que está à mão, disponível a todos, mas que resiste à discursividade crítica por conta de um pacto social de silêncio (e um dos exemplos possíveis é o uso dos jornais, um ponto que nos remete diretamente à carta de Freud em Roma e seu comentário sobre as várias edições diárias propagandeadas pelos entregadores). ${ }^{39}$

Se a principal característica operativa da noção de atenção flutuante em Freud, segundo a leitura de Crary, era sua oscilação dinâmica entre pertencimento e desprendimento, pode-se dizer que essa ambivalência segue operativa também na obra de Sebald. Aquilo, no entanto, que era ainda incipiente em Freud - a atenção flutuante como procedimento ligado ao caminhar - e dicotômico em Debord - a imagem do espetáculo ainda distância de uma crítica e uma autocrítica -, ganha um desdobramento crítico em Sebald, com sua tendência reiterada de apresentar as imagens não como emergências "espontâneas" do espetáculo, mas sempre a partir de um percurso do corpo no tempo e no espaço, a partir das derivas. A articulação entre atenção flutuante e deriva permite a Sebald tomar imagens e objetos não como elementos fixos - monumentalizados ou fetichizados - dentro de uma história que se mostra progressivamente, mas, pelo contrário, como elementos de uma recomposição criativa da história, que leva em conta a descontinuidade produtiva de tempos e espaços.

Kelvin Falcão Klein: Professor Adjunto da Escola de Letras da Universidade Federal do Estado do Rio de Janeiro (UNIRIO).

\footnotetext{
${ }^{39}$ Douglas Pompeu apresenta uma situação que serve de exemplo e que diz respeito à relação de Sebald com os jornais (ou seja, um material central para a lógica da sociedade do espetáculo, um material que não tem valor intrínseco e que pode ser ressignificado em sua apropriação): "Um grande número de imagens [utilizadas por Sebald] são retiradas de recortes de jornal. As quatro caixas [dos arquivos de Sebald] referentes a Austerlitz estão cheias deles. Sebald trabalhou como jornalista, (...) e, ao que indica seu espólio, foi leitor assíduo de jornais. A leitura de jornais é uma prática significativa e corrente tanto do narrador quanto de Austerlitz, e o jornal parece atuar na narrativa como uma vitrine para o cenário cotidiano do crime e da catástrofe de onde muitas vezes os personagens iniciam suas divagações". In: POMPEU, Douglas Valeriano. Op. cit. p. 149.
} 